\title{
The glomerular hyperfiltration of diabetes is not associated with elevated plasma levels of glucagon and growth hormone
}

\author{
M.J. Wiseman, S. Redmond, F. House, H. Keen and G. C. Viberti \\ Unit for Metabolic Medicine, United Medical and Dental Schools of Guy's and St. Thomas’s Hospitals, Guy’s Hospital, London, UK
}

\begin{abstract}
Summary. Plasma concentrations of glucagon, growth hormone and glucose were measured hourly during an ordinary treatment day in 11 Type 1 (insulin-dependent) diabetic patients with high glomerular filtration rate, 11 Type 1 diabetic patients with normal glomerular filtration rate matched for age, diabetes duration and sex, and five healthy control subjects, simultaneously with the measurement of the glomerular filtration rate using ${ }^{51} \mathrm{Cr}$ EDTA clearance. Plasma glucagon profiles were not statistically distinguishable $(p=0.49)$ from control values in either group, although they were somewhat lower in the hyperfiltering group. Plasma growth hormone values were higher than control $(p=0.07)$ in both diabetic
\end{abstract}

groups, but were not different between these two groups $(p=0.94)$. All indices of glycaemic control (glycosylated haemoglobin, urinary glucose excretion, and plasma glucose concentration) were higher in the hyperfiltering group, although no single index reached statistical significance. No correlations between concentrations of these substances and glomerular filtration rate were found. Elevated plasma concentrations of glucagon and growth hormone do not characterise those diabetic patients with high glomerular filtration rate.

Key words: Insulin-dependent diabetes, glomerular filtration rate, glucagon, growth hormone, plasma glucose.
A proportion of Type 1 (insulin-dependent) diabetic patients maintain an elevated glomerular filtration rate (GFR) for many years after diagnosis [1, 2, 3]. Analogous haemodynamic alterations in the kidneys of nondiabetic and diabetic animals have been shown to aggravate the severity of glomerular lesions $[4,5,6]$. Identification of the mechanisms underlying this hyperfiltration in the human diabetic may allow modification of early haemodynamic changes and perhaps inhibit the development of later structural damage [7]. Acute elevations of blood glucose and glucagon to supraphysiologic levels and short-term administration of growth hormone have been shown to increase the GFR 6-10\% above baseline, both in normal and insulin-dependent subjects, although there is controversy on the effects of glucose [8-15]. Based on these findings it has been claimed that these substances, the concentrations of which may be raised in diabetes, are responsible for the high GFR of these patients. Moderate degrees of hyperglycaemia, ranging between 10 and $14 \mathrm{mmol} / \mathrm{l}$, have been found to be associated with high GFR values in some, but not all, cross-sectional studies [15, 16]. However, it is not known whether higher plasma concentrations of glucagon and growth hormone occur in those diabetic patients with persistently high GFR (compared to those with normal GFR) under ordinary conditions of life. We have therefore measured plasma concentra- tions of glucagon, growth hormone and glucose in a group of Type 1 (insulin-dependent) diabetic patients with elevated GFR, in a matched group of insulin-dependent diabetic patients with normal GFR, and a group of healthy control subjects.

\section{Subjects and methods}

Subjects were recruited from the diabetic clinic at Guy's and Mayday Hospitals. Inclusion criteria were: age between 16 and 50 years, duration of diabetes between 2 and 20 years, body mass index between 18.5-22.7 for females and 20.0-24.4 for males, no medication other than insulin, true insulin-dependence, absence of proliferative retinopathy, persistent Albustix-positive proteinuria, elevated blood pressure according to WHO Criteria ( $>160 / 95 \mathrm{mmHg}$ ), known previous cardiovascular or renal disease and urinary tract infection. All diabetic patients were selected after screening for GFR. The normal range in our laboratory for a healthy population aged $18-59$ (mean 34$)$ years is $84-135 \mathrm{ml} / \mathrm{min} / 1.73 \mathrm{~m}^{2}$ [16]. A group of eleven Type 1 (insulin-dependent) diabetic patients with high GFR was matched for age, duration of diabetes and sex with a group of 11 diabetic patients with normal GFR. Five healthy subjects were studied as a control group. All gave informed consent to the study which was approved by the Guy's Hospital Ethical Committee. Clinical data are given in Table 1.

Fasting subjects were admitted to the Metabolic Ward on the morning of the study. No attempt was made to change the usual diet or insulin. An indwelling teflon cannula (Venflon) was inserted into an antecubital vein at 08.00 hours under local anaesthesia, and fasting blood was withdrawn for glycosylated haemoglobin, plasma glucose, glucagon, growth hormone and free insulin concentrations. With the 
Table 1. Clinical details of the three test groups

\begin{tabular}{|c|c|c|c|c|c|c|}
\hline & $M: F$ & $\begin{array}{l}\text { Age } \\
\text { (years) }\end{array}$ & $\begin{array}{l}\text { Diabetes } \\
\text { duration } \\
\text { (years) }\end{array}$ & $\begin{array}{l}\text { GFR } \\
\left(\mathrm{ml} \cdot \mathrm{min} / 1.73 \mathrm{~m}^{2}\right)\end{array}$ & $\begin{array}{l}\text { Insulin dose } \\
\mathrm{U} / \mathrm{kg} / \text { day }\end{array}$ & $\begin{array}{l}\text { Blood pressure } \\
(\mathrm{mmHg})\end{array}$ \\
\hline Normofiltering diabetic patients & $9: 2$ & $31 \pm 10$ & $8 \pm 3$ & $\begin{array}{c}112 \pm 10 \\
(93-130)\end{array}$ & $\begin{array}{l}0.76 \\
(0.41-1.19)\end{array}$ & $\frac{118 \pm 12}{78 \pm 7}$ \\
\hline
\end{tabular}

Figures are mean \pm standard deviation and/or range in parentheses

exception of glycosylated haemoglobin, all determinations were repeated hourly until 17.00 hours. Breakfast was taken at 08.30 hours preceeded, in the diabetic patients, by their usual insulin injection at 08.00 hours. Subjects were given an injection of $70 \mu \mathrm{Ci}{ }^{51} \mathrm{Cr}$-EDTA at 09.30-hours to re-measure GFR, with 11 blood samples being taken over $405 \mathrm{~min}$ to eliminate inaccuracy for high GFRs [17]. Test day GFR was consistent with screening values $(r=0.95, p<0.001)$, and all patients remained in the GFR group to which they were originally allocated. A timed urine collection was made over the whole experimental period for glucose and albumin excretion.

Plasma glucose was measured by a glucose oxidase method (Analox GM 6), glucagon [18] and growth hormone (Phadebas hGh PRIST, Pharmacia, Uppsala, Sweden) by radioimmunoassay (RIA), and plasma free insulin by RIA after polyethylene glycol precipitation of antibody-bound insulin [19]. Interassay coefficients of variation for the glucagon and growth hormone assays were $10.1 \%$ and $8.3 \%$ respectively. Glycosylated haemoglobin was measured by electrofocussing [20] after saline incubation. Urinary albumin concentration was measured by RIA [21].

\section{Statistical analysis}

Data were analysed using the unpaired Student's t-test and the Wilcoxon rank sum test as appropriate. Data were also examined by analysis of variance for repeated measures using the GENSTAT package [22] and F ratios were subjected to the Greenhouse-Geisser correction for repeated measurements [23]. Results are expressed as mean \pm standard deviation.

\section{Results}

Plasma glucagon, growth hormone and glucose profiles for the three groups of subjects are shown in Figure 1. Mean plasma glucagon at 8 of the 10 time points was lower in the hyperfiltering than normofiltering diabetic patients. However, the wide variation in control values ensured that neither group showed a significant difference from control at any time point $(p=0.49)$. Analysis of variance revealed no evidence of differing time trends from group to group. Plasma growth hormone profiles were similar in the two groups, although mean growth hormone concentration was lower in the hyperfiltering than the normofiltering group at 17.00 hours $(p<0.02)$. Using analysis of variance, growth hormone showed significant changes with time in all groups $(p<0.05)$, in keeping with the episodic nature of growth hormone secretion. Both diabetic groups had higher growth hormone concentrations than control $(p=0.07)$, but there was no difference between the two groups $(p=0.94)$. Mean plasma glucose concentration was higher at each time point from 08.00 to 17.00 hours in the hyperfiltering group, although at no time did this difference reach conventional levels of significance. Similarly, mean glycosylated haemoglobin and urinary glucose excretion tended to be higher in the hyperfiltering group. [Glycosylated haemoglobin: $9.7 \pm 2.7$ vs $8.7 \pm 1.3 \%$; urinary glucose excretion: $0-1077$ (geometric mean 80 ) vs $0-470$ (geometric mean 49 ) $\mathrm{mmol} / 24 \mathrm{~h}$ ]. There was no significant difference between the group means for glucose, glucagon or growth hormone. Ninety-five percent confidence limits for differences in mean values between hyperfiltering and normofiltering subjects are given in Table 2 .

Urinary albumin excretion was within the normal range $(<12 \mu \mathrm{g} / \mathrm{min})$ in all but one of the hyperfiltering patients $(23.0 \mu \mathrm{g} / \mathrm{min})$ and two of the normofiltering patients $(26.9$ and $59.0 \mu \mathrm{g} / \mathrm{min}$ ). Mean albumin excretion rate was not different between the two groups (5.7 vs $7.4 \mu \mathrm{g} / \mathrm{min}$ ).

Multiple regression analysis showed no linear correlation between GFR and glucagon, growth hormone or glucose concentrations. Plasma free insulin concentrations did not differ between the two diabetic groups hyperfilterers $29.4 \pm 26.5$ vs normofilterers $24.2 \pm 10.4$ $\mathrm{mU} / 1)$.

\section{Discussion}

The recognition of functional abnormalities in the early stages of diabetes [1-3] may provide a theoretical basis for elucidating the pathogenesis of later clinical diabetic nephropathy and renal failure $[4-6,24]$. The mechanisms underlying elevated GFR, a condition possibly contributing to the development of late diabetic nephropathy, are partly unexplained. Eight days of insulin treatment in newly-diagnosed diabetic patients induces a universal reduction of GFR [25, 26], some patients approaching normal GFR (possibly to become normofiltering diabetics), while GFR in others unaccountably remains high. The mechanisms responsible for the original GFR elevation and the later maintenance of hyperfiltration may not be identical, but these data have led 

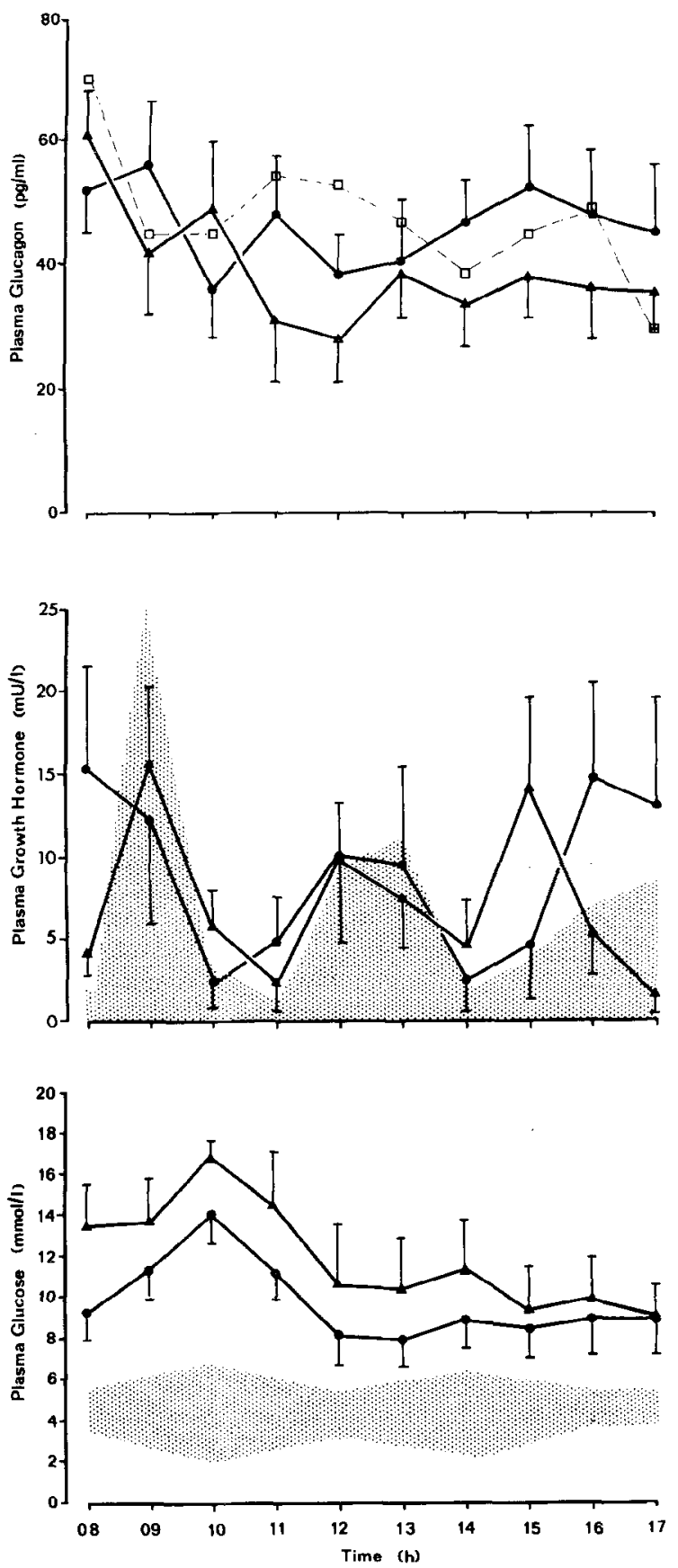

Fig.1. Mean glucagon, growth hormone and glucose profiles in diabetic patients with high GFR $(\boldsymbol{\Lambda})$ ) and normal GFR $(-\mathbf{C})$. Control values for glucagon are given as mean ( $\square--\square$ ) Stippled areas represent the normal range as mean $\pm 2 \mathrm{SD}$ of the control group for growth hormone and glucose

Table 2. $95 \%$ confidence limits of difference in mean concentrations of 3 variables between hyperfiltering and normofiltering diabetic groups

\begin{tabular}{lll}
\hline Variable & Difference & $95 \%$ confidence limits \\
\hline Glucagon $(\mathrm{pg} / \mathrm{ml})$ & -6.7 & -14.6 to +31.0 \\
Growth hormone $(\mathrm{mU} / 1)$ & +0.07 & -1.39 to +3.19 \\
Glucose $(\mathrm{mmol} / \mathrm{l})$ & +1.3 & -3.0 to +4.6 \\
\hline
\end{tabular}

to the suggestion that the high GFR of diabetes is, at least in part, rapidly reversible and mediated by disturbances of glucose counter-regulatory hormones in the poorly controlled diabetic state [25]. A number of studies indicate that glucose, glucagon and growth hormone can increase GFR $[8-13,27,28]$ in diabetic and non-diabetic patients. Elevated plasma concentrations of both these hormones have been implicated in the maintenance of the persistently raised GFR of typically poorly controlled diabetic patients under ordinary conditions of insulin treatment [10-13]. Our findings are not consistent with this assumption.

The two diabetic groups were well matched for age and diabetes duration, but completely separated in terms of GFR. It is possible that, although the GFR was within the normal range, some "normofiltering" patients could be hyperfiltering above their putative nondiabetic GFR, but this is difficult to prove. Moreover, the hyperfiltering group must have consisted exclusively of diabetic patients with supranormal GFR, and this distinguishes the two groups. It might also be possible that some of the normofiltering patients could be falling through the normal range from a high GFR, but this is excluded by the fact that all patients were persistently Albustix-negative [29].

All indices of glycaemic control tended to be higher in the diabetic group with high GFR. However, the large overlap between the groups and the small numbers obscure any possible real but small difference. Furthermore, different patients with the same degree of hyperglycaemia can have widely different GFRs; certain levels of moderate hyperglycaemia can be associated either with normal or very high GFR in different subjects [16]. Table 2 shows that mean plasma glucose concentration could have been up to $4.6 \mathrm{mmol} / 1$ greater in the hyperfiltering subjects without this study detecting a significant difference. Such a difference might account, at least in part, for the higher GFR in hyperfiltering diabetic subjects, but if so, the large overlap in glucose concentrations makes it poosible that hyperfiltering subjects may respond to glucose in an exaggerated way.

No significant difference was found between the two diabetic groups with respect to plasma glucagon profiles; there was, in fact, a tendency for the hyperfiltering group to have lower plasma glucagon concentrations, possibly mediated through increased renal clearance. Furthermore, no correlation was found. Neither diabetic group was insulin-deprived, so the normal plasma glucagon levels in the face of hyperglycaemia are not surprising. Glucagon infusion can elevate glomerular function within minutes $[10,11]$, and our measurements were made simultaneously with the GFR determination. Thus our data are at variance with the view that increased plasma glucagon concentration mediates the high GFR in these patients, some of whom were poorly controlled. Nevertheless, a real increase of more than $31 \mathrm{pg} / \mathrm{ml}$ in mean plasma glucagon is unlikely to have been missed by our study (Table 2), and such an elevation is far less than that required to raise GFR [ 10 , 11]. 
Growth hormone can take 1 week to affect GFR [12, $13,30]$. However, we found no difference between the diabetic groups on this sample day. It is highly unlikely that only one group or the other had, for some reason, growth hormone profiles on this day unrepresentative of the previous few days. Thus, abnormal elevation of plasma growth hormone concentrations did not distinguish the diabetic patients with high GFR from those with normal GFR. The glomerular response to identical circulating levels of growth hormone, however, may be different between these groups.

Our data are consistent with the view that plasma glucose may in part mediate the high GFR in these patients, but fail to support the hypothesis that elevated plasma glucagon and growth hormone concentrations, while capable of elevating GFR under certain circumstances, actually play a prime role in the genesis of the high GFR. Our data cannot exclude the possibility that glomerular sensitivity to these hormones and/or glucose is different between the two groups; it may be possible that local intrarenal hormonal or metabolic responses to the systemic milieu $[31,32]$ may be more important than the milieu itself.

\section{References}

1. Mogensen CE, Østerby R, Gundersen HJG (1979) Early functional and morphologic vascular renal consequences of the diabetic state. Diabetologia 17: 71-76

2. Mogensen CE, Steffes MW, Deckert T, Christiansen JS (1981) Functional and morphological renal manifestations in diabetes mellitus. Diabetologia 21: 89-93

3. Mauer SM, Steffes MW, Brown DM (1981) The kidney in diabetes. Am J Med 70: 603-612

4. Steffes MW, Brown DM, Mauer SM (1978) Diabetic glomerulopathy following unilaterial nephrectomy in the rat. Diabetes 27 : 35-41

5. Mauer SM, Steffes MW, Axar S, Sandberg SK, Brown DM (1978) The effects of Goldblatt hypertension on development of the glomerular lesions of diabetes mellitus in the rat. Diabetes 27 : 738-744

6. Hostetter TH, Rennke HG, Brenner BM (1982) The case for intrarenal hypertension in the initiation and progression of diabetic and other glomerulopathies. Am J Med 72: 375-380

7. Keen H, Wiseman MJ, Viberti GC (1982) Diabetic microvascular disease and metabolic dysregulation. In: Woolf $\mathrm{N}$ (ed) Biology and pathology of the vessel wall. Praeger, Eastbourne, New York, pp189-196

8. Christiansen JS, Frandsen M, Parving HH (1981) The effect of intravenous insulin infusion on kidney function in insulin-dependent diabetes mellitus. Diabetologia 20: 199-204

9. Christiansen JS, Frandsen M, Parving HH (1981) Effect of intravenous glucose infusion on renal function in normal man and in insulin-dependent diabetics. Diabetologia 21: 368-373

10. Parving HH, Noer J, Kehlet $\mathrm{H}$, Mogensen CE, Svendsen PAa, Heding L (1977) The effect of short-term glucagon infusion on kidney function in normal man. Diabetologia 13: 323-325

11. Parving $\mathrm{HH}$, Christiansen JS, Noer I, Tronier B, Mogensen CE (1980) The effect of glucagon infusion on kidney function in short-term insulin-dependent diabetes mellitus. Diabetologia 19: 350-354

12. Christiansen JS, Gammelgaard J, Ørskov H, Anderson AR, Telmer S, Parving HH (1981) Kidney function and size in normal subjects before and during growth hormone administration for one week. Eur J Clin Invest 41: 487-490

13. Christiansen JS, Gammelgaard J, Frandsen M, Ørskov H, Parving
HH (1982) Kidney function and size in type I (insulin-dependent) diabetic patients before and during growth hormone administration for one week. Diabetologia 22: 333-337

14. Mogensen CE (1971) Glomerular filtration rate and renal plasma flow in normal and diabetic man during elevation of blood sugar levels. Scand J Clin Lab Invest 28: 177-182

15. Mogensen CE (1973) Elevated glomerular filtration rate in insulin-treated short term diabetes: non-dependence on blood sugar value. Acta Med Scand 194: 559-561

16. Wiseman MJ, Viberti GC, Keen H (1984) Threshold effect of plasma glucose in the glomerular hyperfiltration of diabetes. Nephron 38: $257-260$

17. Veall N, Gibbs GP (1982) The accurate determination of tracer clearance rates and equilibrium distribution volumes from single injection plasma measurements using numerical analysis. In: Joekes MM, Constable AR, Brown NJG, Tauxe WN (eds) Radionuclides in nephrology, 5th International Symposium, Academic Press, Grune and Stratton, London, pp 125-130

18. Ørskov H, Thomsen HG, Yde H (1968) Wick chromatography for rapid and reliable immunoassay of insulin, glucagon and growth hormone. Nature 219: 193-195

19. Gerbitz KD, Sumner J (1981) Distribution of insulin in blood of Type I diabetics. Diabetologia 21: 274

20. Jeppson IO, Franzen B, Nilsson K (1978) Determination of the glycosylated haemoglobin fraction $\mathrm{HbA1} C$ in diabetes mellitus by thin-layer electrofocussing. Sci Tools 25: 69-72

21. Keen $H$, Chlouverakis $C$ (1963) An immunoassay for urinary albumin at low concentrations. Lancet 2: 913-916

22. Genstat: a general statistical programme (1977). Rothamsted Experimental Station

23. Winer JB (1971) Statistical principles in experimental design. McGraw Hill, London, p 523

24. Parving HH, Viberti GC, Keen $H$, Christiansen JS, Lassen NA (1983) Haemodynamic factors in the genesis of diabetic microangiopathy. Metabolism 32: 943-949

25. Christiansen IS, Gammelgaard J, Tronier B, Svendsen PA, Parving $\mathrm{HH}$ (1982) Kidney function and size in diabetics before and during initial insulin treatment. Kidney Int 21: 683-688

26. Mogensen CE, Andersen MJF (1975) Increased kidney size and glomerular filtration rate in untreated juvenile diabetes: normalisation by insulin treatment. Diabetologia 11:221-224

27. Brøchner-Mortensen J (1973) The glomerular filtration rate during moderate hyperglycaemia in normal man. Acta Med Scand 194: 31-37

28. Brøchner-Mortensen J (1973) Glomerular filtration rate and extracellular fluid volumes during normoglycaemia and moderate hyperglycaemia in diabetics. Scand J Clin Lab Invest 32: 311-316

29. Mogensen CE, Christensen CK (1984) Predicting diabetic nephropathy in insulin-dependent patients. N Engl J Med 311: $89-93$

30. Parving HH, Noer I, Mogensen CE, Svendsen PAa (1978) Kidney function in normal man during short-term growth hormone infusion. Acta Endocrinol 89: 796-800

31. Schnermann J, Briggs JP (1981) Participation of renal cortical prostaglandins in the regulation of glomerular filtration rate. Kidney Int 19: 802-815

32. Blantz RC, Petersen OW, Gushwa L, Tucker BJ (1982) Effect of modest hyperglycaemia on tubuloglomerular feedback activity. Kidney Int 22 (Suppl 12): 206-212

Received: 21 March 1985

and in revised form: 1 August 1985

Dr. M.J.Wiseman

Unit for Metabolic Medicine

United Medical and Dental Schools

of Guy's and St Thomas's Hospitals

4th Floor Hunt's House

Guy's Hospital

London SE1 9RT

UK 